\title{
DESIGN AND INSTALLATION OF A CAMERA NETWORK ACROSS AN ELEVATION GRADIENT FOR HABITAT ASSESSMENT
}

Christopher W. Bater *

Faculty of Forest Resources Management,

University of British Columbia, 2424 Main Mall, Vancouver, BC, V6T 1Z4, Canada.

Nicholas C. Coops

Faculty of Forest Resources Management,

University of British Columbia, 2424 Main Mall, Vancouver, BC, V6T 1Z4, Canada.

Michael A. Wulder

Canadian Forest Service (Pacific Forestry Centre), Natural Resources Canada, 506 West

Burnside Road, Victoria, BC, V8Z 1M5, Canada

Scott E. Nielsen

Department of Renewable Resources, University of Alberta

Edmonton, Alberta.

Greg McDermid

Foothills Facility for Remote Sensing and GIScience,

Department of Geography, University of Calgary, 2500 University Drive, NW, Calgary,

Alberta, T2N 1N4, Canada

Gordon B. Stenhouse

Foothills Research Institute, Hinton, Alberta, T7V 1X6, Canada

* corresponding author:

Phone: +1 (604) 827 4429, Fax :+1 (604) 8229106

email: cbater@interchange.ubc.ca

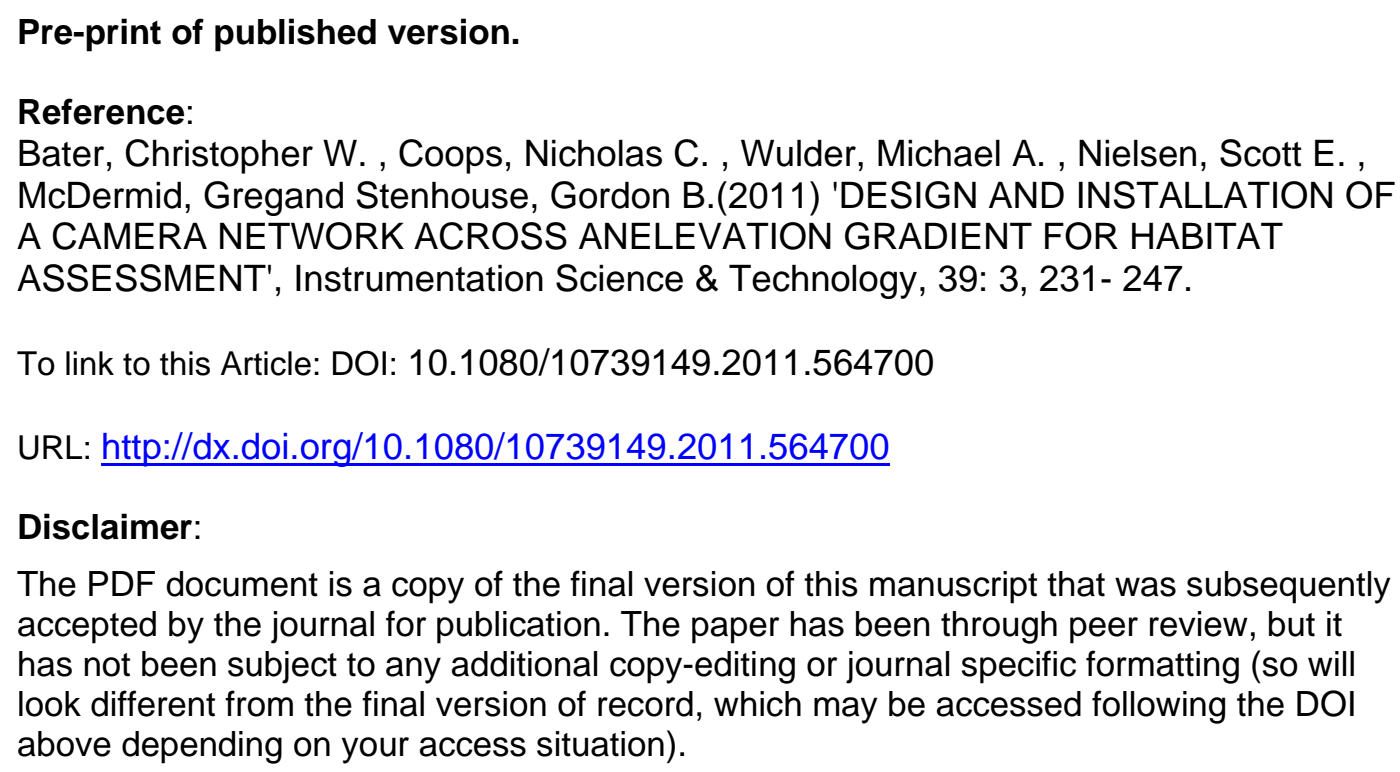




\section{ABSTRACT}

Developments in distributed sensing, web camera image databases, and automated data visualisation and analysis, among other emerging opportunities, have resulted in a suite of new techniques for monitoring habitat at many different scales. Data from these networks can provide important information on the timing of plant phenology with implications for habitat status and condition. In this paper we describe the design and deployment of a small network of cameras established along an elevation gradient in western Alberta, Canada, with the purpose of developing a more comprehensive understanding of seasonal phenophases and the reproductive timing (budding, fruit production) of understorey forest vegetation. During an eight month period in 2009, over 6,700 images were acquired across seven sites throughout the growing season, providing a rich dataset documenting phenological activity of both the under- and overstorey forest components. Strong elevation and climate responses were observed. A mathematical function was fitted to the data to demonstrate the capacity to capture phenological trends. This paper demonstrates the utility of these types of relatively inexpensive, portable systems for monitoring seasonal vegetation development and change at high temporal resolutions across landscapes.

\section{INTRODUCTION}

Phenology is the study of the timing of recurring biological events, such as leaf emergence or animal migrations. ${ }^{[1]}$ The vegetation phenological cycle defines the onset (start of season) and duration of a photosynthetically active canopy which, for example, influences the magnitude of carbon and water fluxes between the atmosphere and biosphere. ${ }^{[2-4]}$ As a result, vegetation phenology plays a crucial role in the carbon balance of terrestrial ecosystems ${ }^{[4-8]}$, and changes in the timing of plant developmental phases may signal important inter-annual climatic variations. ${ }^{[7,9,10]}$

In addition to influencing carbon uptake in forested ecosystems, the phenological cycle is also a critical driver of resource availability and quality for a wide range of wildlife. For instance, many ungulate species follow temporally and spatially the seasonal 'green wave' in plant productivity. ${ }^{[11,12]}$ In some cases this may even lead to long-distance seasonal movements or migrations of populations along altitudinal or seasonal rainfall gradients to maximize resource availability and quality. ${ }^{[11,13,14]}$ In many ecosystems, particularly grasslands and alpine, the relationship between the seasonal green wave phenomenon and wildlife habitat can be measured using a normalized difference vegetation index (NDVI) or other remote sensing indices. ${ }^{[1,15,16]}$ However, for non-herbivore wildlife species and in habitats where vegetation is structurally more complex (e.g. forests), phenological indices from satellites such as NDVI are unlikely to directly relate to seasonal wildlife habitat quality, since resources being sought are not necessarily herbaceous. For instance, the omnivorous grizzly bear (Ursus arctos L.) relies on a diverse array of food resources that often includes herbaceous vegetation, but also roots, hard and soft mast, small mammals, ungulates (often neonates), spawning salmon, or insects, all of which follow a highly predictable seasonal progression (phenology) of use based on availability and nutritional quality. ${ }^{[17-19]}$ Seasonal phenology is therefore a driving force in defining critical habitat for this focal conservation species. ${ }^{[20,21]}$ Thus, for many species, additional methods are needed to relate on-the-ground phenological events to ecological processes and wildlife habitat, as well as to determine whether these relationships can be predicted directly or indirectly by remote sensing technologies. 
Traditionally, assessment of plant phenology has relied on a network of observers, often volunteers and amateur naturalists, who record discrete events such as flowering, leaf emergence, and other characteristics depending upon location and specific observation goals. ${ }^{\text {[22] }}$ These networks, however, are typically made at a very limited number of sites using a range of methodologies by a large number of personnel with variable levels of skill. In contrast, satellite remote sensing technologies can provide detailed information on vegetation phenology; however, it is acquired at large spatial scales (often $500 \mathrm{~m}$ spatial resolution or greater), ${ }^{[2,4,7]}$ making species-specific phenological events difficult to ascertain and predict. As a result, linking scales of observation from the individual leaf to the landscape is an ongoing challenge. ${ }^{[1]}$

The increasing popularity and widespread use of inexpensive visible spectrum digital cameras in recent years offer notable potential in the monitoring and measurement of phenological events. ${ }^{[23-25]}$ Repeat photography allows a very fine temporal sampling, often at daily or hourly intervals, for monitoring vegetation phenology. By mounting these systems on towers, other vertical objects, or surface platforms, data can be acquired at an intermediate scale of observation, providing a link between field-based observation methods and satellite-derived estimates. This intermediate scale of observation, sometimes referred to as "near" remote sensing, allows high temporal and spatial resolution datasets to be developed.

Many of the early applications of camera technology to studies of phenology started in agriculture. ${ }^{[26]}$ For instance, Purcel1 ${ }^{[27]}$ utilised digital cameras to detect changes in wheat and soybean canopies at a one metre spatial resolution over a growing season. Graham et al. ${ }^{\text {[23] }}$ acquired daily images of mosses during drying and moistening cycles to develop a comprehensive understanding of their changing status under different climatic conditions. Richardson et al. ${ }^{[22]}$ mounted a commercially available digital camera and web system on a $\mathrm{CO}_{2}$ flux tower to observe deciduous vegetation green-up and compare it to changes in the fraction of the photosynthetically active radiation absorbed by the canopy. A network of similar instruments is being proposed for a larger number of flux tower sites across North America, with potential integration with the National Ecological Observation Network (NEON; for a description see ${ }^{[28]}$ ). Graham et al. ${ }^{[25]}$ recently assembled a dataset consisting of freely available images from across North America collected using public internet-connected digital cameras. The ground-based image data were used to model spring green-up and were then compared to co-located satellitederived estimates. Graham et al. ${ }^{[25]}$ demonstrated that the ground-based cameras were able to detect green-up with equal or better accuracy than the satellite data, and that the cameras were superior in terms of data gaps and consistent image quality. With increasing interest in the available technologies, as well as global growth in citizen sensing and distributed science management, the role of these types of instruments is likely to increase, with broadening use beyond the conventional applications in phenology and climate, including application to biodiversity and conservation management.

In this paper we describe the development and installation of a small network of phenological cameras across an elevation gradient in an isolated area of western Alberta, Canada. The objective of the overall study is twofold: first, to assess the capacity of the network to detect changes in key over- and understorey elements of the forest canopy, particularly for plant species important to grizzly bears as a food source; second, to develop a near-surface based dataset with which to compare and validate simultaneously-acquired satellite-derived reflectance and phenology estimates. The first objective has been addressed by Bater et al. ${ }^{[2]}$, who explain the targeting of specific understorey and overstorey species for phenological monitoring in a forested 
environment. Coops et al. ${ }^{[30]}$ outline the application of the camera network towards the second objective, where key indicators of phenological activity from the ground-based network are compared with those derived from a time series of $30 \mathrm{~m}$ spatial resolution synthetic Landsat scenes generated at 14 day intervals. Presently, in this foundational paper, we describe the camera network, including the design characteristics of the system, the installation across the elevation gradient, examples of the initial datasets, and the nature of trends obtained from the system over the first eight month acquisition period.

\section{MATERIALS AND METHODS}

\subsection{Study Area}

The foothills flanking the Alberta Rocky Mountains, Canada, are a diverse region containing a mix of mature and young forest, open meadow alpine areas, provincial and national parks, and resource extraction activities, including forestry, oil and gas exploration and development, and open pit mining. A $90 \mathrm{~km}$-long transect centered over the town of Robb, Alberta $\left(53.22^{\circ} \mathrm{N}\right.$, $\left.116.98^{\circ} \mathrm{W}\right)$, was designed to capture a range of phenological changes and growing season attributes across known grizzly bear habitat. Cameras were installed at seven sites. Six were selected in pairs at three low to moderate elevation zones to reflect the two main biomes present along the transect. At each elevation, one paired site was placed within a coniferous dominated stand, while the second was located in a mixed overstorey species site consisting of between $20-$ $40 \%$ deciduous canopy. A single site was established in a high elevation coniferous stand. However, at this elevation no paired deciduous stand could be found. Details on the sites, including vegetation composition and location characteristics are summarized in Table 1.

\section{2 Digital Camera Network Setup}

To promote accessibility and portability of the system design, we used standard commercially available digital camera systems designed for extended outdoor use. The seven time-lapse packages were manufactured by Harbortronics (Fort Collins, Colorado, USA), and each consisted of a Pentax digital single lens reflex (DSLR) camera slaved to an intervalometer, both of which were sealed in a fiberglass case (Figure 1). The cameras had $23.5 \times 15.7 \mathrm{~mm} \mathrm{CCD}$ sensors with either 6.1 or 10.2 million effective pixels. The camera lenses had a variable focal length of 18-55 mm and each camera was installed with a 4 GB SD memory card. Many of the advanced camera settings were disabled, including automatic focus, shake reduction, and flash. In addition to the camera, an iButton data logger (model DS1921G, Dallas Semiconductor Corp.) was installed to record temperature at each site four times daily.

Cameras were mounted on trees within each of the plots. Candidate trees were tall and dominant in the canopy with no low branches to obstruct the view of the plot. Cameras were mounted approximately three meters above the ground pointing north, while the temperature loggers were installed on the north side of a tree $0.6 \mathrm{~m}$ above the ground.

Each camera was set to record five high quality JPEG images per day between 12:00 noon and 1:00 pm local time. Digital images were archived as high quality JPEG images (2000 x 3008 pixel or 2592 x 3872 pixel resolution with 3 channels of 8 bit RGB data). Although "non-lossy" TIF or RAW formats may have been preferable, the extended period of time the cameras were deployed without field visits necessitated the use of compressed files. Exchangeable image file (exif) data was recorded with each image and included a date and time stamp for easy reference. 


\subsection{Image analysis:}

Our analysis approach adapted the methods described by Richardson et al. ${ }^{[22]}$, Ahrends et al. ${ }^{[31]}$, and Richardson et al. ${ }^{[32]}$ A custom script was written in Python and images were read sequentially regardless of meteorological conditions or image quality. When required, images were resampled to $2000 \times 3008$ pixels using a nearest neighbour approach. Otherwise, no smoothing or filtering was performed to ensure overall objectivity.

Using regions of interest or masks is a commonly accepted method for analyzing specific portions of ground-based images. For example, Ahrends et al. ${ }^{[31]}$ employed regions of interest to isolate portions of individual tree crowns from a mixed canopy beneath a flux tower. Ide and Oguma $^{[33]}$ employed regions of interest to isolate individual species where image resolution and range allowed. Graham et al. ${ }^{[25]}$ segmented images into deciduous, evergreen and understorey regions for analysis. We developed regions of interest by first tessellating images using a 50 x 50 pixel image-wide grid over the entire frame, which was held constant throughout a given time series. Each cell could be considered a sub-region, and by merging these, larger regions of interest were developed for analysis. As the sub-regions were typically smaller than a given vegetation element at the plant scale, they provided a framework to easily and consistently develop the larger regions which were subsequently analyzed. For each site, regions of interest were developed at several scales, including single scene-wide regions consisting of all vegetation within view, regions separating understorey and overstorey, and regions delineating individual plants or species groups. Regions of interest were also placed over elements not expected to exhibit a phenological signal, including large tree stems and open sky.

The overall brightness (red DN + green DN + blue DN) was calculated and used to normalize the brightness of each channel such that the red, green and blue fractions were calculated as channel percent $(\%)=$ channel DN / total RGB DN. Three additional band ratios were also computed. The first ratio, referred to as the vegetation green excess index or $2 \mathrm{G}-\mathrm{RBi}$, was originally developed by Woebbecke et al. ${ }^{[34]}$ and has been repeatedly demonstrated to be a robust indicator of changing vegetation phenology. ${ }^{\text {e.g. } 22,32,33]}$ The $2 \mathrm{G}-\mathrm{RBi}$ index was calculated as $(2 *$ green DN) - (red DN + blue DN). Simple ratios of the raw red to green channels and blue to green channels were also calculated. Finally, the mean of the five images captured each day was calculated for each ratio or index.

Once the various band ratio and index values were calculated for each region of interest within the images, curves were fit to the data to estimate green-up. A variety of equations have been employed to model vegetation phenology. For example, Zhang et al. ${ }^{[3]}$ used logistic functions to estimate phenologically important dates from Moderate Resolution Imaging Spectroradiometer (MODIS) data. Fisher et al. ${ }^{[35]}$ employed pairs of logistic growth sigmoid functions to estimate leaf onset and offset from Landsat data, noting that their curve-fitting methodology was extendable across a range of spatial scales. Richardson et al. ${ }^{[32]}$ employed two sigmoid curves multiplied together to estimate spring green-up and autumn senescence from web camera imagery. In order to quantitatively assess the differences in the change in green-up over the elevation transect, we fitted a sigmoid-shaped function (Equation 1), which has been shown previously to capture changes in vegetation: ${ }^{[\text {e.g. } 22]}$

$$
f(x)=a+\frac{b}{1+e^{(c-d x)}}
$$


where the $a$ and $b$ are parameters controlling the scaling of the function between the minimum and maximum observed values, and $c$ and $d$ result in shifts in the response variable $x$, time or day of year. An important characteristic of the sigmoid function is that the ratio of the $c$ and $d$ parameters provides an estimate of the day of year where the function achieves its half maximum (known as the seasonal-midpoint technique) which has been shown to predict the initial leaf expansion of broadleaf forests ${ }^{[36,37]}$, and which has the advantage over other techniques in that it is sensitive to site-specific variations and, as a result, may be more sensitive to local changes in leaf area. ${ }^{[38]}$ The function was applied to the normalized three band spectral data and ratios individually. The $c$ and $d$ parameters were used to estimate half maximums.

\subsection{Validation of green-up dates:}

As a validation exercise, understorey green-up dates determined using the sigmoid function parameters were compared to visual estimates. ${ }^{[\text {e.g. } 31,33,35]}$ For each site, the time series was visually inspected. The green-up date was subjectively estimated as the first day when the majority of the understorey region of interest was light green. ${ }^{\text {[e.g. 33] }}$

\section{RESULTS}

Following installation, a total of 6,732 images were collected from the seven sites over a single growing season in 2009, ranging from day of year 103 to 300 (or spring snow melt and subsequent green-up, through to the first autumn snow fall). Camera failure rates due to battery power, camera resetting, and miscues totaled less than $10 \%$ of the total yield of photos. As would be expected, image quality varied over the eight month installation period due to variable lighting conditions caused by rain, fog, snow, and cloud cover. Example images from a pair of the mid-elevation sites are shown in Figures 2 and 3. These images demonstrate the variability of the scenes across the elevation gradient with respect to the overstorey and understorey composition, as well as snow cover at the commencement and end of the growing season.

To demonstrate that the camera-derived vegetation indices are sensitive to phenology, seasonal changes in the green fraction are shown for four regions of interest at two sites (Figure 4). At the Fickle Lake Conifer site, one region of interest is placed over a spruce stem, while the second covers the majority of the observable vegetation through the stand (both over- and understorey). Similarly, at the Cadomin Conifer site, one region of interest is place over open sky, while the second is again placed over all vegetation within the scene. Periods of snow cover are also highlighted (Figure 4). These examples show the strong phenological signal produced by changing vegetation throughout the season. In comparison, the regions of interest covering the spruce stem and sky, which should exhibit little or no change, are relatively stable. For all regions of interest, snow cover in particular has a noticeable effect on the values of the green fraction. This is the result of image-wide shifts in colour temperature towards blue hues when snow is present, which in turn causes a reduction in the values of the green fraction.

Results of the validation exercise are show in Table 3, as are the parameters derived from fitting sigmoid functions to understorey $2 \mathrm{G}-\mathrm{RBi}$ data. Figure 5 shows the locations of the regions of interested employed in the validation. The day of year of the beginning of the green-up period as estimated using the camera data were based on the $c / d$ parameters, while the visual estimates were based on when the majority of the understorey appeared to be light green. The camera at the Cadomin Mixed site failed during the green-up period, so the green-up date could not be included in the validation. When the two methods were compared, the mean absolute difference 
between the two were 4.7 days ( $n=6$ sites, standard error of the mean $= \pm 0.95$ days). The sigmoid function fitted the start of green up closely. The ratio of the $c / d$ parameters provides an indication of the half maximum green-up time, and demonstrates that, as expected, the lower elevation sites had earlier green-up dates than the higher elevation sites. Coniferous sites across the transect were more similar than the mixed sites, which contained a significant proportion of deciduous vegetation. A comparison of the sigmoid functions fitted to the $2 \mathrm{G}-\mathrm{RBi}$ data from the seven sites is shown in Figure 6.

\section{DISCUSSION AND CONCLUSION}

Initial analysis of data from the transect of phenological cameras indicates that standard, commercially available digital camera systems designed for extended outdoor time-lapse deployment can be used to extract information on canopy and understorey phenology. Given that these cameras are relatively inexpensive, require little in the way of maintenance, and are commercially available, their placement over a range of sites and conditions are more readily achievable than with systems which rely on external power sources and internet connectivity.

The $2 \mathrm{G}-\mathrm{RBi}$ index appears to be sensitive to vegetation change, producing high model correlations that were superior to those achieved using the individual normalized bands or other indices. The fact that these ratios performed more consistently than individual brightness changes is logical given the day to day variations in illumination which occur within the frame. Other image derivatives being explored include those described by Proulx and Parrott ${ }^{[39,40]}$, including mean information gain, which is related to structural complexity. Additional information related to different canopies' responses may be extracted from these data, and may in fact lead to a better understanding of the phenology of smaller regions within the scene, such as discrete areas of understorey which contain species critical for habitat and food resources for many animals. ${ }^{[29]}$

In this application we have focused our initial analysis on green-up, which is essentially the development of green vegetation within the field of view. As digital camera technology becomes more common for monitoring vegetation, other researchers are correlating responses with fluxes related to carbon and water, such as $\mathrm{CO}_{2}$ exchange, leaf area index, and the fraction of absorbed photosynthetically active radiation. ${ }^{\left[\text {e.g. }{ }^{32]}\right.}$ Additional instrumentation co-located with the camera network would be required to investigate these additional aspects of forest function. However, information on of the timing and location of vegetation phenological phases is critical to understanding the behavior and habitat usage of animals such as grizzly bears, and we believe the application of these systems to biodiversity-related issues is a logical and important extension of ongoing work.

We readily acknowledge that these inexpensive systems have some disadvantages when compared to other technologies. The observed brightness changes are essentially uncalibrated. We have no reference panel in the field of view to allow correction of atmospheric effects, and detailed information on in-camera image processing and the spectral sensitivity of the CCD sensor itself is often difficult to obtain from the manufacturers. As a result, computation of reflectance from the camera data is not possible. However, the development of inexpensive, commercially available systems, such as the one described in this paper, will be critical to improving our understanding of seasonal variations in vegetation phenology, the detection of changing vegetation dynamics for biodiversity and wildlife management, and for the calibration of datasets obtained from other remote sensing technologies. 


\section{ACKNOWLEDGEMENTS}

Sam Coggins (University of British Columbia) and David Laskin (University of Calgary) were members of the deployment team. Andrew Richardson (Harvard University) and Scott Ollinger (University of New Hampshire) provided initial advice and enthusiasm for the network plans. Dr Thomas Hilker (UBC) provided programming assistance. Funding for this research was generously provided by the Grizzly Bear Program of the Foothills Research Institute located in Hinton, Alberta, Canada, with additional information available at http//

foothillsresearchinstitute.ca

\section{REFERENCES}

[1] Morisette, J.T.; Richardson, A.D.; Knapp, A.K.; Fisher, J.I.; Graham, E.A.; Abatzoglou, J.; Wilson, B.E.; Breshears, D.D.; Henebry, G.M.; Hanes, J.M.; Liang, L. Tracking the rythm of the season in the face of global change: phenological research in the 21st century, Front. Ecol. Environ., 2009, 7, 253-260.

[2] Botta, A.; Viovy, N.; Ciais, P.; Friedlingstein, P.; Monfray, P. A global prognostic scheme of leaf onset using satellite data, Global Change Biol., 2000, 6, 709-725.

[3] Zhang, X.; Friedl, M.; Schaaf, C.; Strahler, A.; Hodges, J.; Gao, F.; Reed, B.; Huete, A. Monitoring vegetation phenology using MODIS, Remote Sens. Environ., 2003, 84, 471475 .

[4] Jolly, W.M.; Nemani, R.; Running, S.W. A generalized, bioclimatic index to predict foliar phenology in response to climate, Global Change Biol., 2005, 11, 619-632.

[5] Keeling, C.D.; Chin, J.F.; Whorf, T.P. Increased activity of northern vegetation inferred from atmospheric CO2 measurements, Nat., 1996, 382, 146-149.

[6] Kang, S.; Running, S.W.; Lim J.-H.; Zhao, M.; Park, C.; Loehman, R. A regional phenology model for detecting onset of greenness in temperate mixed forests, Korea: an application of MODIS leaf area index, Remote Sens. Environ., 2003, 86, 232 - 242.

[7] White, M.A.; Nemani, R.R. Canopy duration has little influence on annual carbon storage in the deciduous broad leaf forest, Global Change Biol., 2003, 9, 967-972.

[8] Badeck, F.W.; Bondeau, A.; Bottcher, K.; Doctor, D.; Lucht, W.; Schaber, J.; Sitch, S. Responses of spring phenology to climate change, New Phytol., 2004, 162, 295-309.

[9] Reed, B.C.; Brown, J.F.; VanderZee, D.; Loveland, T.R.; Merchant, J.W.; Ohlen, D.O. Measuring phenological variability from satellite imagery, J. Veg. Sci., 1994, 5, 703-714.

[10] Xiao, J.; Moody, A. Photosynthetic activity of US biomes: responses to the spatial variability and seasonality of precipitation and temperature, Global Change Biol., 2004, 10, 437-451.

[11] Hebblewhite, M.; Merrill, E.; McDermid, G. A multi-scale test of the forage maturation 
hypothesis for a partially migratory montane elk population, Ecol. Monogr., 2008, 78, 141166.

[12] Zweifel-Schierlly, B.; Kreuzer, M.; Ewald, K.C.; Suter, W. Habitat selection by an Alpine ungulate: the significance of forage characteristics varies with scale and season, Ecography, 2009, 32, 103-113.

[13] Frank, D.A.; McNaughton, S.J.; Tracy, B.F. The ecology of the Earth's grazing ecosystems, BioSci., 1998, 48, 513-521.

[14] van der Graaf, S.A.J.; Stahl, J.; Klimkowska, A.; Bakker, J.P.; Drent, R.H. Surfing on a green wave - how plant growth drives spring migration in the Barnacle Goose Branta leucopsis, Ardea, 2006, 94, 567-577.

[15] Merrill, E.H.; Bramble-Brodahl, M.K.; Marrs, R.W.; Boyce, M.S. Estimation of Green Herbaceous Phytomass from Landsat MSS Data in Yellowstone National Park, J. Range Manage., 1993, 46, 151-157.

[16] S. Hamel, M. Garel, M. Festa-Bianchet, J.M. Gaillard, and S.D. Côté, Spring Normalized Difference Vegetation Index (NDVI) predicts annual variation in timing of peak faecal crude protein in mountain ungulates, . J. Appl. Ecol., 2009, 46, 582-589.

[17] Hamer, D.; Herrero, S. In Proceedings of 7th International Conference on Bear Research and Management. Grizzly bear food and habitat in the front ranges of Banff National Park, Alberta. 1987, 199-213.

[18] Mattson, D.J.; Barber, K.; Maw, R.; Renkin, R. Coefficients of productivity for Yellowstone's grizzly bear habitat. Biological science report. U.S. Department of the Interior, US Geological Survey, 2004.

[19] Munro, R.H.M.; Nielsen, S.E.; Price, M.H.; Stenhouse, G.B.; Boyce, M.S. Seasonal and diel patterns of grizzly bear diet and activity in west-central Alberta, J. Mammalogy, 2006, $87,1112-1121$.

[20] Nielsen, S.E.; Boyce, M.S.; Stenhouse, G.B.; Munro, R.H.M. Development and testing of phenologically driven grizzly bear habitat models, Ecosci., 2003, 10, 1-10.

[21] Nielsen, S.E.; Boyce, M.S.; Stenhouse, G.B.; Munro, R.H.M. Grizzly bears and forestry: I. Selection of clearcuts by grizzly bears in west-central Alberta, Canada, For. Ecol. Manage., 2004, 199, 51-65.

[22] Richardson, A.D.; Jenkins, J.P.; Braswell, B.H.; Hollinger, D.Y.; Ollinger, S.V.; Smith, M.L. Use of digital webcam images to track spring green-up in a deciduous broadleaf forest, Oecologia, 2007, 152, 323-334. 
[23] Graham, E.A.; Hamilton, M.P.; Mishler, B.D.; Rundel, P.W.; Hansen, M.H. Use of a networked digital camera to estimate net $\mathrm{CO} 2$ uptake of a desiccation-tolerant moss, Int. J. Plant Sci., 2006, 167, 751-758.

[24] Jacobs, N.; Burgin, W.; Fridrich, N.; Abrams, A.; Miskell, K.; Braswell, B.H.; Richardson, A.D.; Pless, R. In ACM International Conference on Advances in Geographic Information Systems (SIGSPATIAL GIS). The global network of outdoor webcams: properties and applications. 2009.

[25] Graham, E.A.; Riordan, E.C.; Yuen, E.M. Estrin, D.; Rundel, P.W. Public Internetconnected cameras used as a cross-continental ground-based plant phenology monitoring system, Global Change Biol., 2010, 16, 3014-3023.

[26] Adamsen, F.J.; Coffelt, T.A.; Nelson, J.M.; Barnes, E.M; Rice, R.C. Method for using images from a color digital camera to estimate flower number, Crop Sci., 2000, 40, 704709.

[27] Purcell, L.C. Soybean canopy coverage and light interception measurements using digital imagery, Crop Sci., 2000, 40, 834-837.

[28] Keller, M.; Schimel, D.S.; Hargrove, W.W.; Hoffman, F.M. A continental strategy for the National Ecological Observatory Network, Front. Ecol. Environ., 2008, 6, 282-284.

[29] Bater, C.W.; Coops, N.C.; Wulder, M.A.; Hilker, T.; Nielsen, S.E.; McDermid, G.; Stenhouse, G.B. Using digital time-lapse cameras to monitor species-specific understorey and overstorey phenology in support of wildlife habitat assessment, Environ. Monit. Assess., 2010, doi: 10.1007/s10661-010-1768-x

[30] Coops, N.C.; Hilker, T.; Bater, C.W.; Wulder, M.A.; Nielsen, S.E.; McDermid, G.; Stenhouse, G. Linking ground-based to satellite-derived phenological metrics in support of habitat assessment, Remote Sens. Lett., In Press.

[31] Ahrends, H.E.; Brügger, R.; Stöcklii, R.; Schenk, J.; Michna, P.; Jeanneret, F.; Wanner, H.; Eugster, W. Quantitative phenological observations of a mixed beech forest in northern Switzerland with digital photography, J. Geophys. Res., 2008, 113, G04004.

[32] Richardson, A.D.; Braswell, B.H.; Hollinger, D.Y.; Jenkins, J.P.; Ollinger, S.V. Nearsurface remote sensing of spatial and temporal variation in canopy phenology, Ecol. Appl., 2009, 19, 1417-1428.

[33] Ide R.; Oguma, H. Use of digital cameras for phenological observations, Ecol. Informatics, 2010, 5, 339-347.

[34] Woebbecke, D.M.; Meyer, G.E.; Von Bargen, K.; Mortensen, D.A. Color indices for weed identification under various soil, residue, and lighting conditions, Trans. ASAE, 1995, 38, 259-269. 
[35] Fisher, J.I.; Mustard, J.F.; Vadeboncoeur, M.A. Green leaf phenology at Landsat resolution: Scaling from the field to the satellite, Remote Sens. Environ., 2006, 100, 265279.

[36] White, M.A.; Running, S.W.; Thornton, P.E. The impact of growing-season length variability on carbon assimilation and evapotranspiration over 88 years in the eastern US deciduous forest, Int. J. Biometeorol., 1999, 42, 139-145.

[37] Schwartz, M.D.; Reed, B.C.; White, M.A. Assessing satellite-derived start-of-season measures in the conterminous USA, . Int. Journal Climatol., 2002, 22, 1793-1805.

[38] Waring, R.H.; Coops, N.C.; Fan, W.; Nightingale, J.M. MODIS enhanced vegetation index predicts tree species richness across forested ecoregions in the contiguous U.S.A., Remote Sens. Environ., 2006, 103, 218-226.

[39] Proulx, R.; Parrott, L. Measures of structural complexity in digital images for monitoring the ecological signature of an old-growth forest ecosystem, Ecol. Indic., 2008, 8, 270-284.

[40] Proulx, R.; Parrott, L. Structural complexity in digital images as an ecological indicator for monitoring forest dynamics across scale, space and time, Ecol. Indic., 2009, 9,1248-1256. 


\section{LIST OF TABLES}

Table 1: Summary of the camera sites, including forest cover type and coordinates.

\begin{tabular}{|c|c|c|c|c|c|}
\hline Site name & $\begin{array}{c}\text { Longitude } \\
\text { (decimal degrees) }^{1}\end{array}$ & $\begin{array}{l}\text { Latitude (decimal } \\
\text { degrees) }\end{array}$ & $\begin{array}{l}\text { Forest } \\
\text { type }\end{array}$ & Overstorey species & $\begin{array}{l}\text { Elevation } \\
(\mathrm{m})^{1}\end{array}$ \\
\hline Fickle Lake & -116.721 & 53.393 & Coniferous & Mature White Spruce & 951 \\
\hline Fickle Lake & -116.712 & 53.398 & Mixed & $\begin{array}{c}\text { White Spruce, Trembling } \\
\text { Aspen }\end{array}$ & 970 \\
\hline Bryan spur & -116.970 & 53.239 & Coniferous & $\begin{array}{c}\text { black spruce, lodgepole } \\
\text { pine }\end{array}$ & 1,092 \\
\hline Bryan spur & -116.965 & 53.246 & Mixed & $\begin{array}{l}\text { Trembling aspen, lodgepole } \\
\text { pine, white spruce }\end{array}$ & 1,093 \\
\hline Cadomin & -117.288 & 53.066 & Coniferous & $\begin{array}{l}\text { Black spruce, Lodgepole } \\
\text { pine }\end{array}$ & 1,458 \\
\hline Cadomin & -117.321 & 53.044 & Mixed & $\begin{array}{l}\text { White spruce, Balsam } \\
\text { Poplar, willow }\end{array}$ & 1,484 \\
\hline $\begin{array}{l}\text { Prospect } \\
\text { Creek }\end{array}$ & -117.327 & 52.968 & Coniferous & Lodgepole pine & 1,714 \\
\hline
\end{tabular}


Table 2: Descriptions of the intervalometers and cameras employed for the phenology monitoring program

\begin{tabular}{|c|c|c|}
\hline \multirow{4}{*}{ Intervalometer } & Model & Harbortronics Digisnap 2000 \\
\hline & Time of first daily capture & $12: 00$ noon \\
\hline & Number of captures & 5 \\
\hline & $\begin{array}{l}\text { Interval between } \\
\text { captures }\end{array}$ & 12 minutes \\
\hline \multirow{13}{*}{ Camera } & Model & Pentax KX00D digital single lens reflex \\
\hline & Sensor & $\begin{array}{c}23.5 \times 15.7 \mathrm{~mm} \mathrm{CCD} ; \\
6.1 \text { - } 10.2 \text { million effective pixels }\end{array}$ \\
\hline & Lens & $18-55 \mathrm{~mm}, \mathrm{f} 3.5-5.6$ \\
\hline & Memory card & 4 gigabyte SD \\
\hline & File type & High quality JPEG \\
\hline & White balance & Sunlight \\
\hline & & \\
\hline & Mode & Program auto exposure $(P)$ \\
\hline & ISO & 200 \\
\hline & Focus & Manual, set to infinity \\
\hline & Focal length & $18 \mathrm{~mm}$ \\
\hline & Shake reduction & Disabled \\
\hline & Flash & Disabled \\
\hline
\end{tabular}


Table 3: Camera-based and visual estimated dates of green-up. Sigmoid fitting functions for equation 1 for the $2 \mathrm{G}-\mathrm{RBi}$ index are shown. $a$ and $b$ are parameters controlling the scaling of the function between the minimum and maximum observed values, and $c$ and $d$ result in shifts in time (day of year). The ratio of the $c$ and $d$ parameters provides an estimate of the day of year when green-up begins. Note that the parameters have been rounded to two decimal places.

\begin{tabular}{|c|c|c|c|c|c|c|c|c|c|}
\hline \multirow[t]{2}{*}{$\begin{array}{l}\text { Site } \\
\text { name }\end{array}$} & \multirow[t]{2}{*}{$\begin{array}{l}\text { Forest } \\
\text { type }\end{array}$} & \multirow[t]{2}{*}{$\begin{array}{l}\text { Elevation } \\
\qquad(\mathrm{m})^{1}\end{array}$} & \multicolumn{4}{|c|}{$\begin{array}{l}\text { Sigmoid function } \\
\text { parameters }\end{array}$} & \multirow{2}{*}{$\begin{array}{l}\text { Camera-based } \\
\text { estimate of } \\
\text { beginning of } \\
\text { green-up } \\
\text { (day of year) }\end{array}$} & \multirow{2}{*}{$\begin{array}{c}\text { Visual estimate } \\
\text { of beginning of } \\
\text { green-up } \\
\text { (day of year) }\end{array}$} & \multirow[t]{2}{*}{$\begin{array}{l}\text { Difference } \\
\text { (days) }\end{array}$} \\
\hline & & & $a$ & $\boldsymbol{b}$ & $c$ & $d$ & & & \\
\hline $\begin{array}{l}\text { Fickle } \\
\text { Lake }\end{array}$ & Coniferous & 951 & 17.04 & 52.88 & 7.51 & 0.11 & 169 & 165 & 4 \\
\hline $\begin{array}{l}\text { Fickle } \\
\text { Lake }\end{array}$ & Mixed & 970 & 7.24 & 17.97 & 4.72 & 0.08 & 158 & 162 & -4 \\
\hline $\begin{array}{l}\text { Bryan } \\
\text { spur }\end{array}$ & Coniferous & 1,092 & 4.91 & 61.81 & 3.44 & 0.06 & 163 & 171 & -8 \\
\hline $\begin{array}{l}\text { Bryan } \\
\text { spur }\end{array}$ & Mixed & 1,093 & 5.33 & 61.5 & 5.18 & 0.09 & 157 & 154 & 3 \\
\hline Cadomin & Coniferous & 1,458 & 4.77 & 57.74 & 4.22 & 0.07 & 161 & 168 & -7 \\
\hline Cadomin & Mixed & 1,484 & 5.25 & 36.74 & 22.81 & 0.32 & 174 & NA & NA \\
\hline $\begin{array}{l}\text { Prospect } \\
\text { Creek }\end{array}$ & Coniferous & 1,714 & 4.88 & 80.13 & 6.43 & 0.09 & 174 & 172 & 2 \\
\hline
\end{tabular}




\section{LIST OF FIGURES}
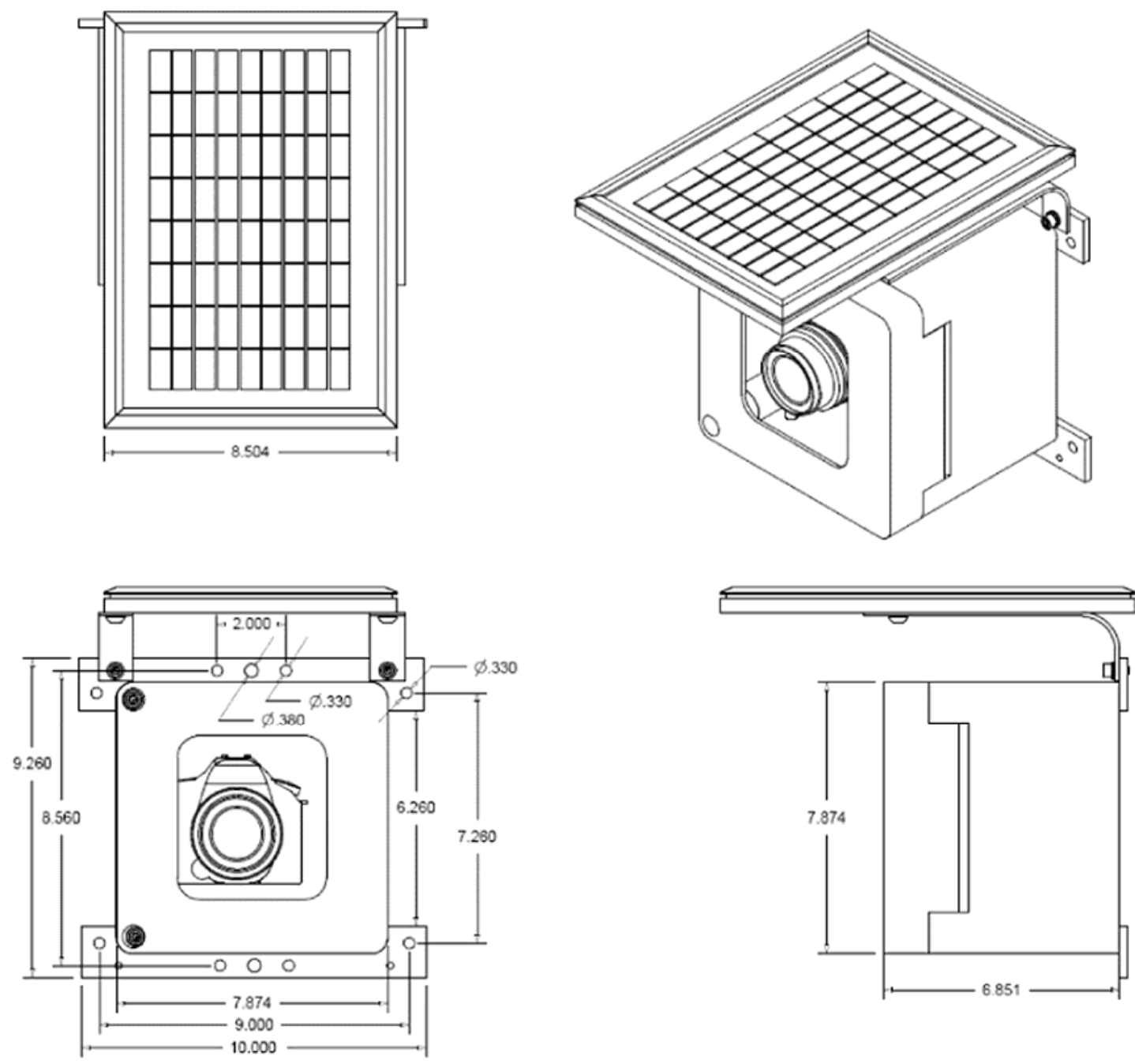

Figure 1. Diagram of the Harbortronics time-lapse camera package. The units consist of a Pentax DSLR slaved to an intervelometer, both of which are powered by a lithium ion battery and solar panel. 

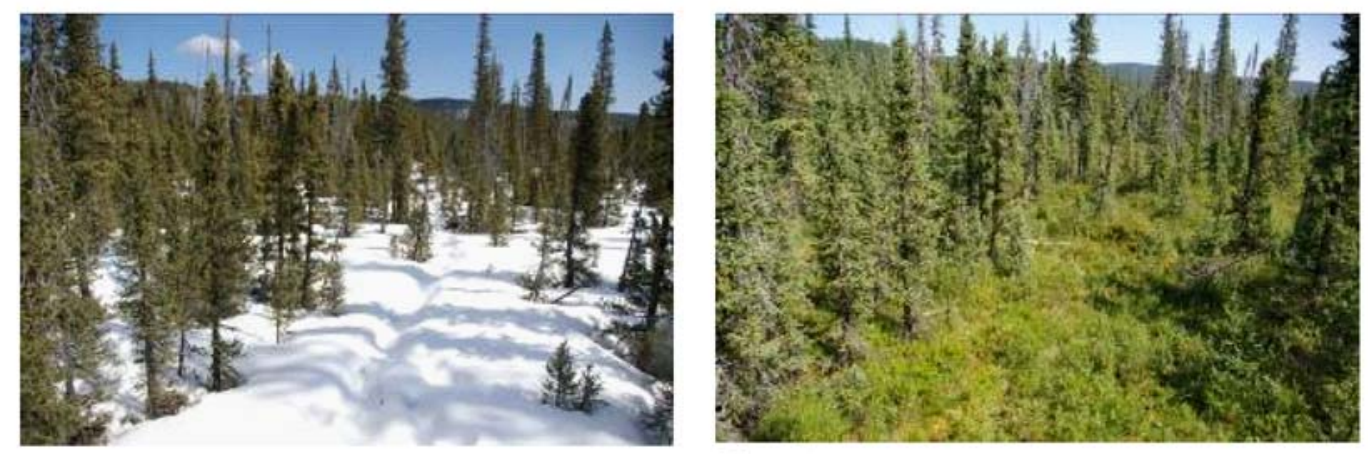

14 April

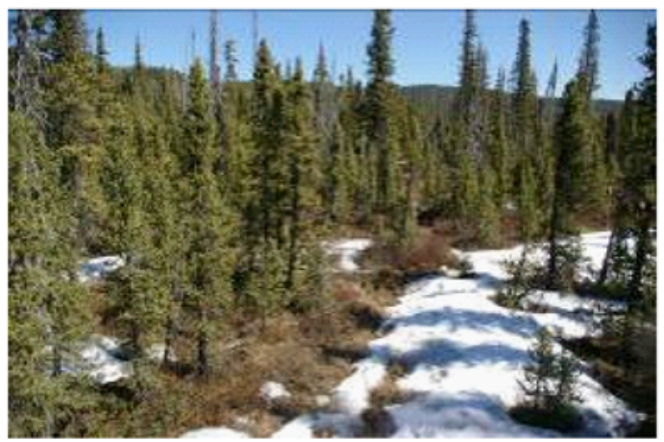

4 May

7 August

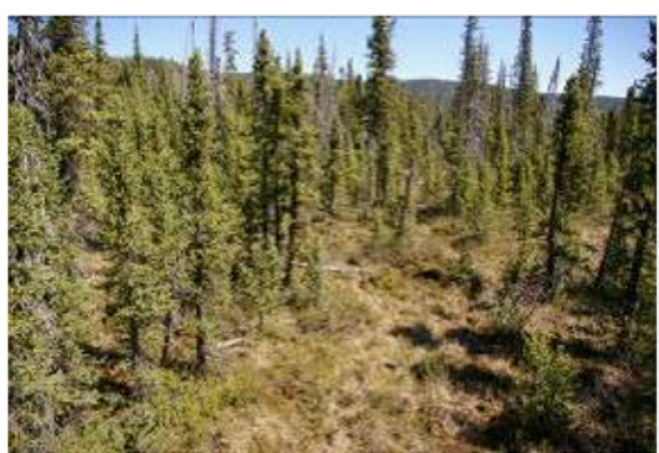

9 June

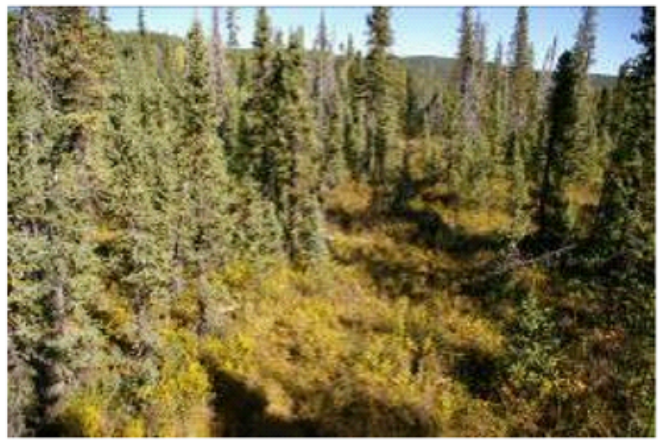

22 September
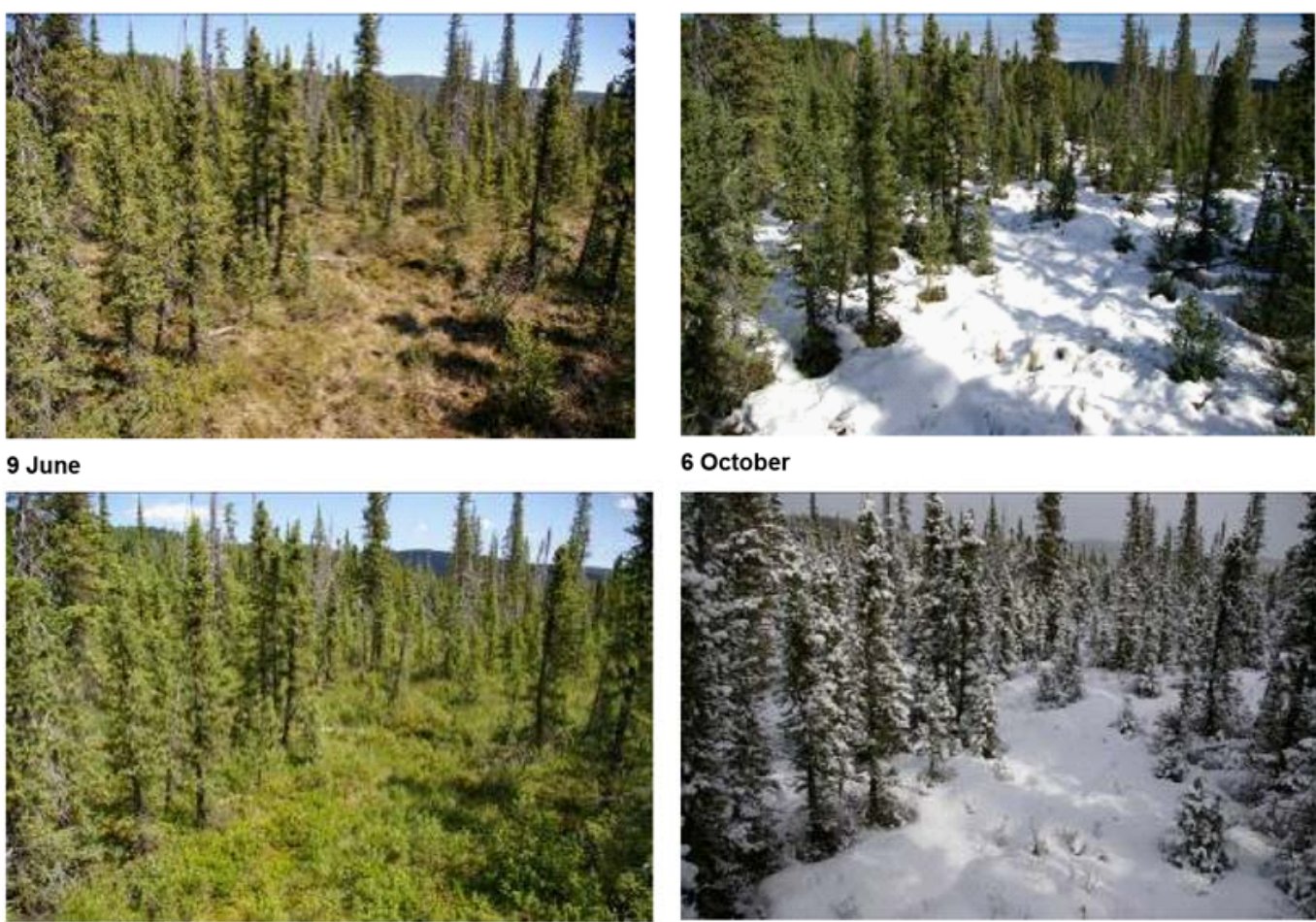

6 October

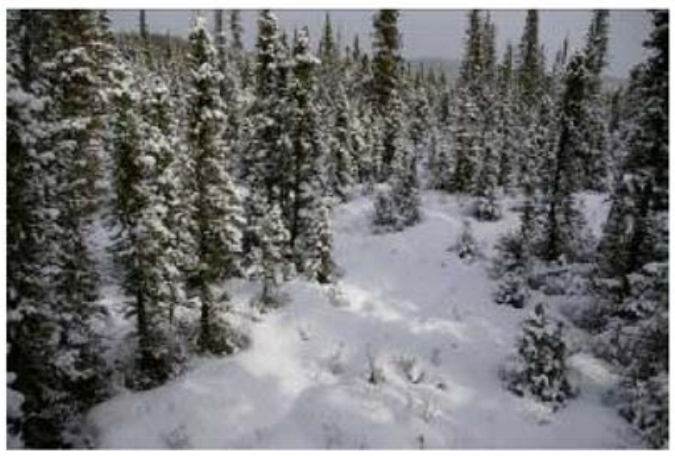

17 July

27 October

Figure 2. Example images from the Cadomin conifer site (see Table 1 for site description). 


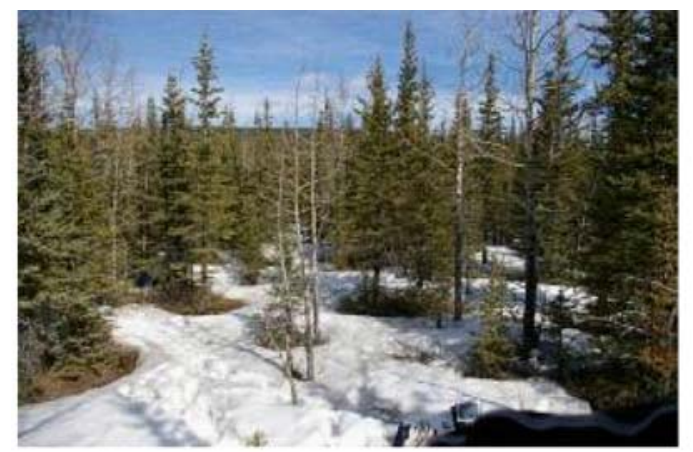

12 April

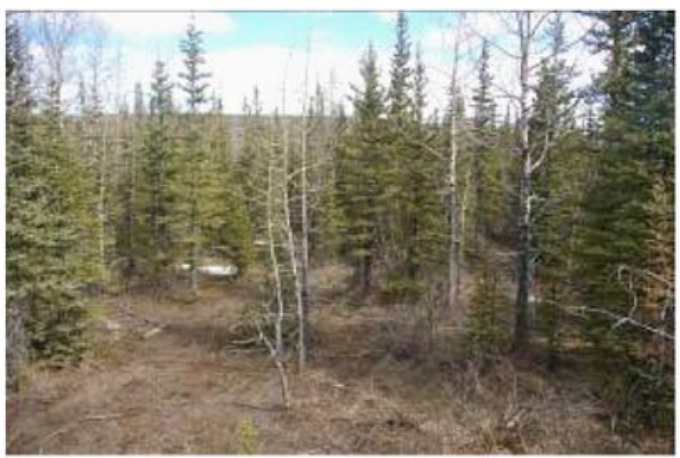

7 May

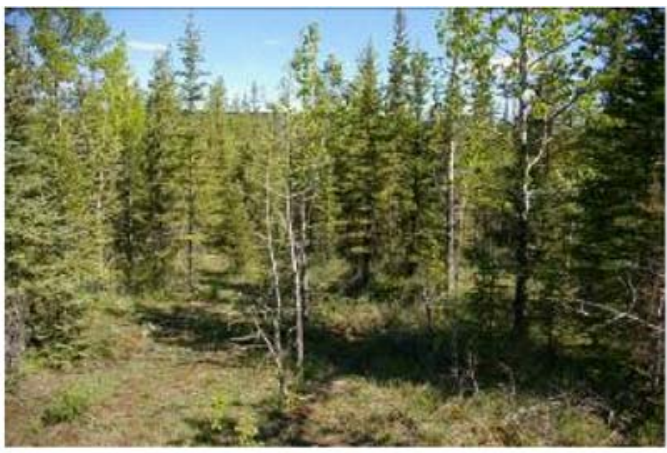

26 June

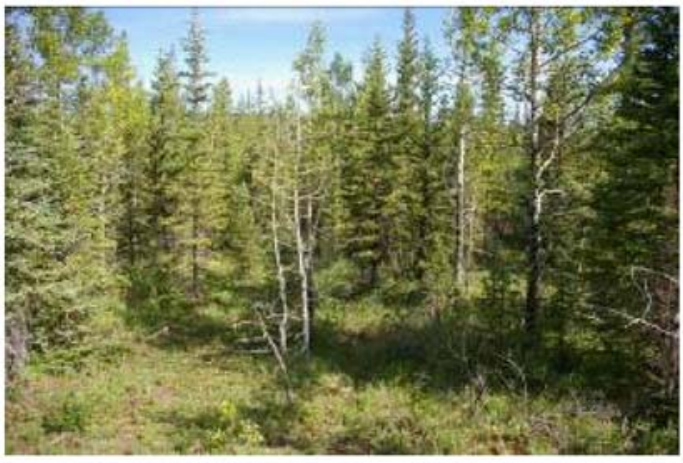

21 July

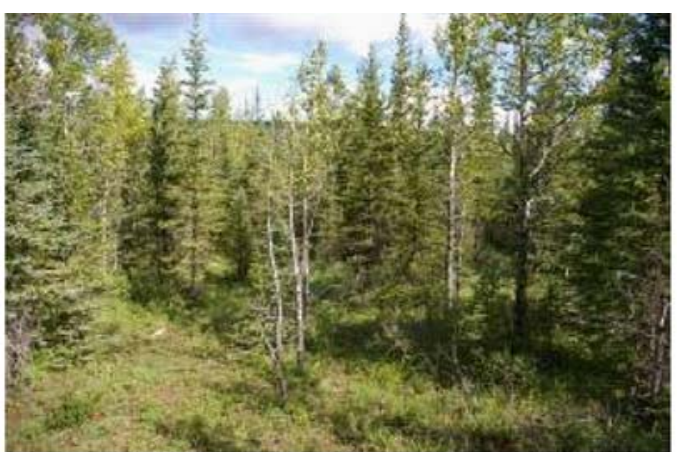

11 August

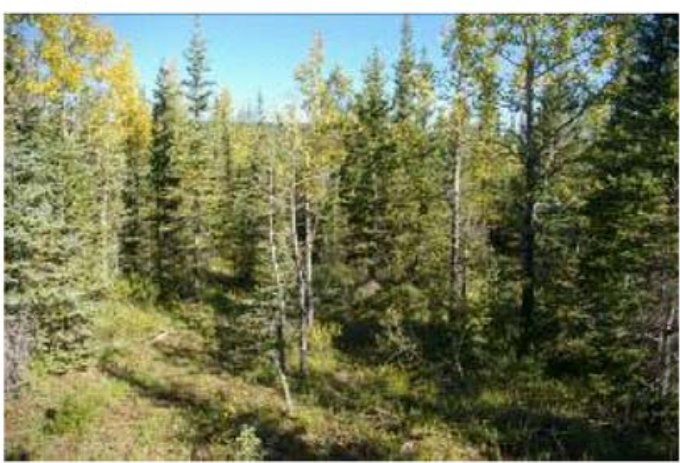

\section{September}

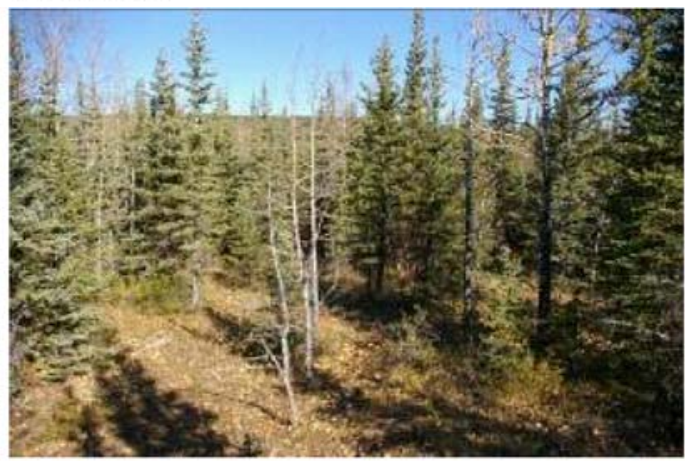

1 October

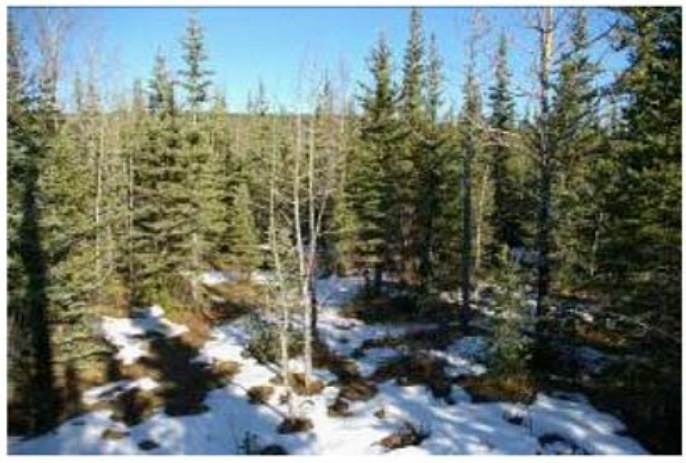

22 October

Figure 3. Example images from the Cadomin mixed site (see Table 1 for site description). 

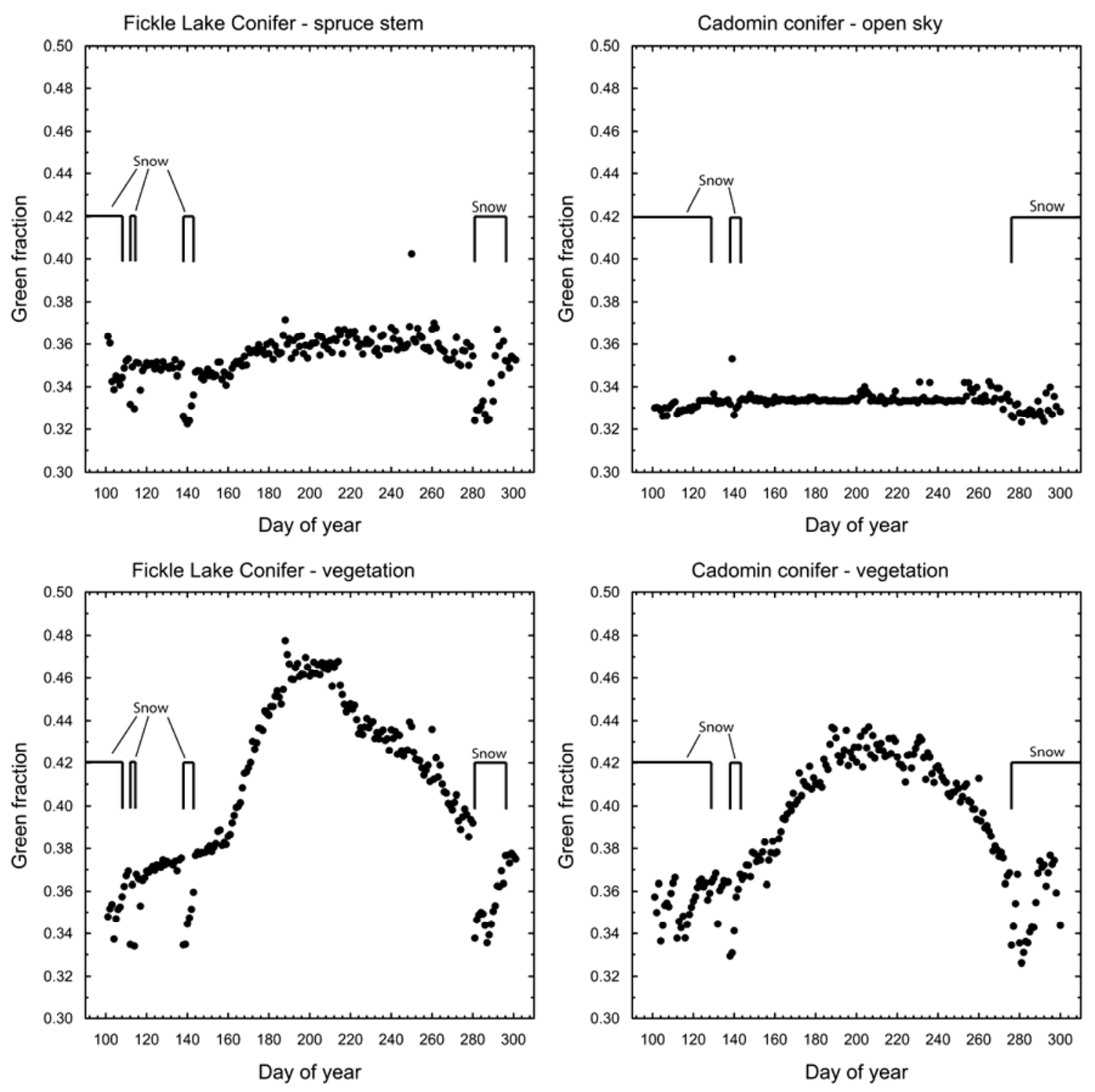

Figure 4. Seasonal changes in green fraction for four regions of interest at two sites. At the Fickle Lake Conifer site, one region covers a spruce stem, while another is established over under- and overstorey vegetation. At the Cadomin conifer site, one region is located over open sky, while the second is again positioned over under- and overstorey vegetation. Periods with snow cover are also highlighted. 


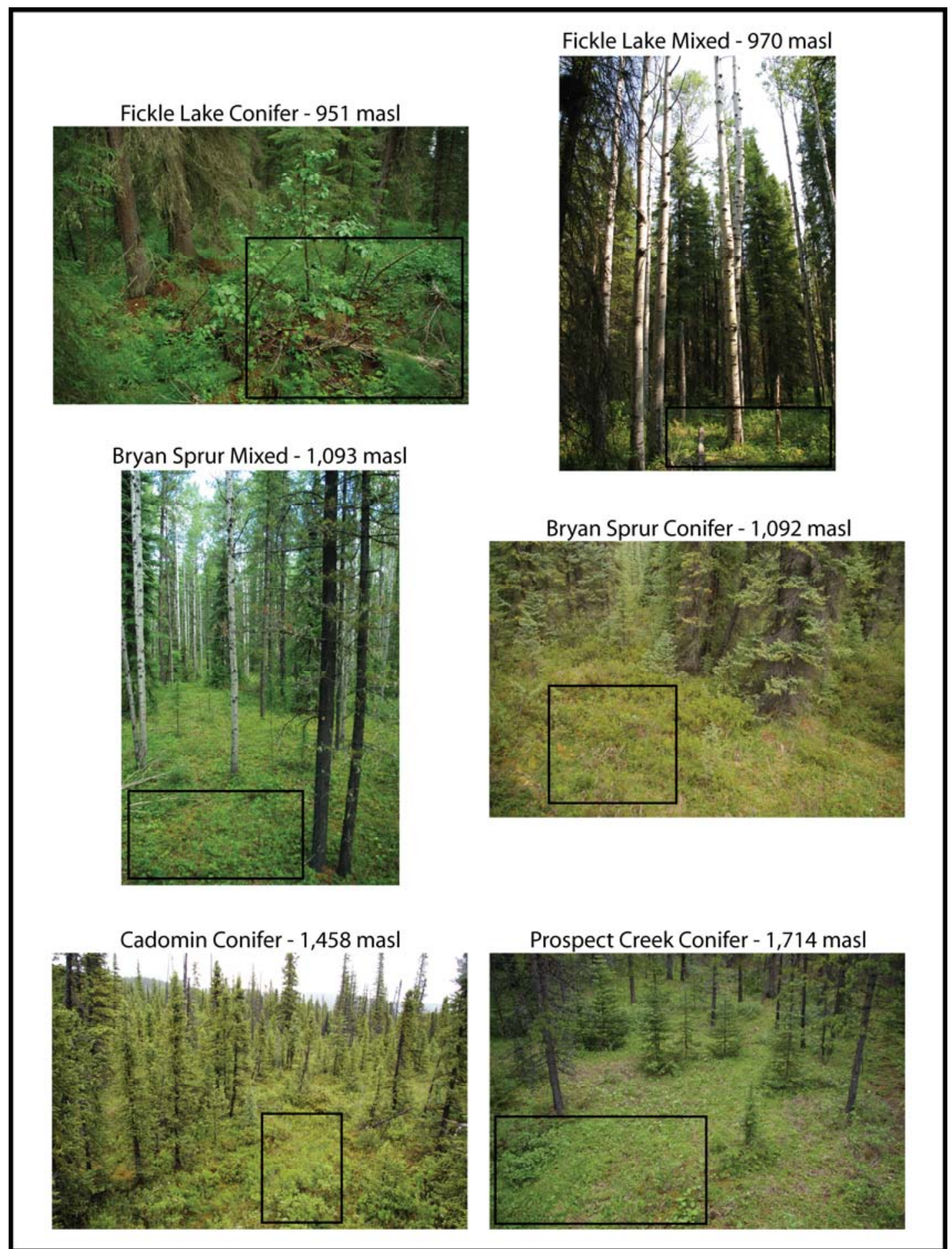

Figure 5. Locations of understorey regions of interest employed in the validation exercise. 


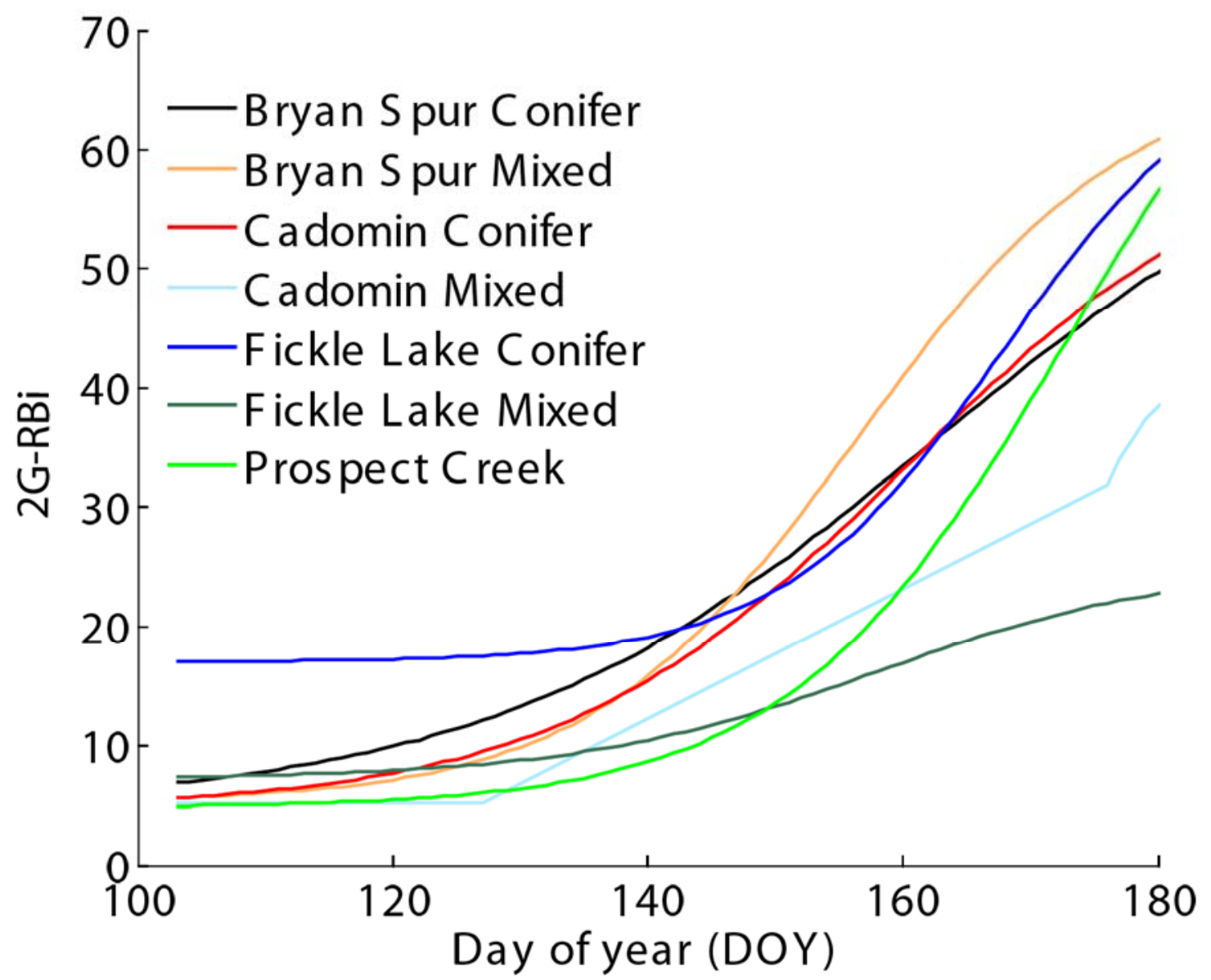

Figure 6. Examples of the $2 \mathrm{G}-\mathrm{RBi}$ trajectories for all sites during spring green-up. 